\title{
Characterization of the effect of wetting-drying cycles on the behaviour of hydrophilic additives in mineral wool
}

\author{
I. Antepara, Z. Pavlík, M. Jerman, M. Pavlíková \& R. Černý \\ Department of Materials Engineering and Chemistry, \\ Faculty of Civil Engineering, Czech Technical University in Prague, \\ Czech Republic
}

\begin{abstract}
Salts and water are assumed to damage historical masonries. Therefore, many conservation treatments have been developed by research teams for the consolidation and protection of porous building materials affected by salt attack. Among them, different methods for obtaining effective desalination of historical masonry were proposed, having smaller or bigger disadvantages. Cellulose is the favourite material added to poultices used in desalination, and hydrophilic mineral wool (HMW) is considered as a possible alternative. Thanks to its hydrophilic additive, HMW allows water transport along the fibres, but contrary to cellulose it is an inorganic material, which reduces the maintenance of the poultice. In this paper, behaviour of the hydrophilic additive in relation to the wetting-drying cycles is studied. Basic characterization of the HMW is performed. Water and chloride absorption coefficients are measured using a standard free water uptake experiment. Additionally, moisture profiles are accessed using gravimetric method, and the moisture diffusivity as a function of moisture content is calculated using an inverse analysis procedure. The measurements are performed on samples pretreated several times in water and $1 \mathrm{M} \mathrm{NaCl}$ water solution. Finally, FTIR and chromatographic analyses of HMW leached in water were performed to verify the assumed leachability of the hydrophilic additive. The measured water and $\mathrm{NaCl}$ water solution transport parameters confirm that HMW can be used in building materials desalination; the observed drop in the water absorption coefficient is explained using the FTIR results.

Keywords: hydrophilic mineral wool, water and salt transport properties, wetting-drying cycles, hydrophilic additive, desalination.
\end{abstract}




\section{Introduction}

Mineral wool based materials are frequently used in various applications, being their most widespread use in building construction for thermal insulation of walls, roofs and floors [1], and also of pipes. Additionally to its thermal properties, they can also offer acoustic insulation, protection against fire, reinforcement of cement, and they allow plant growing when used as synthetic soils in green roofs. Many mineral wool products are provided with hydrophobic substances, because the presence of water in the material is undesirable for the majority of applications. This is the case of thermal insulation properties, which are affected by the presence of moisture. Here, the thermal conductivity of the mineral wool significantly increases with increasing moisture content.

Hydrophilic additives are seldom used in mineral wool products. Practically the only notable application of HMW is in the form of synthetic soils for plant growing (green roofs as a water reservoir [2]), where water saturation of the material is necessary for its proper function. However, the capability of fibrous materials with hydrophilic substances to transport rapidly liquid water [1] make them desirable for a variety of other applications, where such favourable hygric properties can be conveniently employed.

In previous research [1], the low thermal conductivity, the very low capacity of mineral wool for absorption of hygroscopic moisture, and the high water vapour diffusion coefficient were confirmed. All these properties open ways for the application of HMW products in interior thermal insulation systems, in drying-out of flooded buildings [3], and in desalination of historical buildings [4].

The aim of the latter is trying to avoid the action of water soluble salts on historical masonries, which leads to its surface degradation and structural damage. Several degradation mechanisms can be usually recognized, being the most often observed contour scaling, granular disintegration, and efflorescence. Many conservation treatments have been developed by research teams for the consolidation and protection of porous building materials affected by salt attack. For obtaining effective desalination, different methods have being proposed (e.g. cellulose poulticing, reverse osmosis), each of which has one or more advantages, as well as one or more disadvantages. Hence, there is a need for the development of new conservation treatments.

Cellulose is the favourite material added to poultices used in desalination of historical masonry. However, it is organic material with limited durability and functionality. Since HMW is considered as a possible alternative to cellulose, we focused in this paper on detail characterization of its water and salt transport properties. First, basic physical parameters of commercial HMWs are accessed, among them bulk density, matrix density, and total open porosity. Liquid water and salt solutions transport are described on the basis of sorptivity concept using sorption experiment. The behaviour of hydrophilic additive in mineral wool is described under wetting-drying cycles, reusing the same sample several times. Additionally, moisture profiles are measured, both for moisture and $1 \mathrm{M} \mathrm{NaCl}$ water solution penetration, using gravimetric method. These measurements are 
also performed on samples pretreated several times in water. The measured moisture profiles are subjected to an inverse analysis procedure, and moisture diffusivity as function of moisture content is calculated. Finally, FTIR and chromatographic analyses of HMW leached at water were performed in order to verify the assumed leachability of the hydrophilic additive.

\section{Experimental}

HMW material manufactured by Rockwool CZ, potentially applicable for desalination purposes was analysed. HMW board having thickness of $120 \mathrm{~mm}$ originally designed for application in interior thermal insulation system and consisting of hard and soft layer having thickness was characterized as sold. However, except basic physical properties, soft layer (thickness $100 \mathrm{~mm}$ ) is used for the experiments. Fibre layers orientation was not considered in planning the experimental work, as the effect of material anisotropy on the water transport properties of the HMW was found not statistically important [1].

\subsection{Hydrophilic mineral wool characteristics}

After analysing the matrix density $\rho_{\text {mat }}\left(\mathrm{kg} / \mathrm{m}^{3}\right)$ of studied materials by the helium pycnometry, the following fundamental physical material characteristics were attained. The bulk density $\rho_{b}\left(\mathrm{~kg} / \mathrm{m}^{3}\right)$ was determined using the gravimetric method. The total open porosity $\psi\left(\mathrm{kg} / \mathrm{m}^{3}\right)$ was calculated as

$$
\psi=1-\frac{\rho_{b}}{\rho_{\text {mat }}} .
$$

The measurement of basic physical parameters took place in a conditioned laboratory at the temperature of $23 \pm 1{ }^{\circ} \mathrm{C}$ and $25-30 \%$ of relative humidity. Each result represents the average value from four to five measured values. The expanded relative uncertainty of applied testing method is $10 \%$ and is results of materials inhomogeneity mainly.

\subsection{Sorptivity experiment}

The water absorption coefficient $A\left(\mathrm{~kg} / \mathrm{m}^{2} \mathrm{~s}^{1 / 2}\right)$ and the chloride solution absorption coefficient $A_{\mathrm{NaCl}}\left(\mathrm{kg} / \mathrm{m}^{2} \mathrm{~s}^{1 / 2}\right)$ were measured using a standard liquid uptake experiment [5]. The particular specimens were water and vapour-proof insulated on four lateral sides and their face sides were immersed 1-2 mm into the distilled water or $1 \mathrm{M} \mathrm{NaCl}$ water solution. The automatic balance allowed recording the increase of sample mass. The absorption coefficients were then calculated using Eq. (2)

$$
i=A \cdot \sqrt{t},
$$

where $i\left(\mathrm{~kg} / \mathrm{m}^{2}\right)$ is the cumulative mass of water or salt solution, $t(\mathrm{~s})$ is the time from the beginning of the suction experiment. The water or salt solution 
absorption coefficient was then employed for the calculation of the apparent moisture diffusivity $\kappa_{a p p}\left(\mathrm{~m}^{2} / \mathrm{s}\right)$ in the form

$$
\kappa_{a p p} \approx\left(\frac{A}{w_{s a t}}\right)^{2},
$$

where $w_{\text {sat }}\left(\mathrm{kg} / \mathrm{m}^{3}\right)$ is the saturated moisture content $[6,7]$ measured for water and chloride solution penetration.

As previously stated, the same sample was used several times. Before reusing the sample, the samples were dried at room temperature or at temperature of $60^{\circ} \mathrm{C}$ in different positions: as taken from the system over a surface, as taken from the system over a paper, with water-proof not insulated faces in vertical position and with water-proof not insulated faces in horizontal position.

\subsection{Moisture profiles}

For determination of moisture diffusivity as function of moisture content, moisture profiles were measured at first. The measurements were done on samples having dimensions of $40 \times 20 \times 300 \mathrm{~mm}$, without waterproofing the lateral sides of the samples. The samples were put by their face side in contact with water, whereas the measurements were performed both in vertical and horizontal direction of water intake. This experimental arrangement allowed quantify the effect of gravity on moisture transport that was assumed to be very significant. After chosen time interval of water penetration (10, 20, $30 \mathrm{~min}$.), the particular samples were cut into $10 \mathrm{~mm}$ thick pieces, and the moisture content in each piece was determined by gravimetric method. The same was done with samples subjected to wetting-drying cycles. For the calculation of moisture diffusivity, inverse analysis of experimentally measured transient moisture profiles was done. The water mass balance was expressed by the non-linear diffusion equation simplified to its 1-D form,

$$
\frac{\partial u}{\partial t}=\frac{\partial}{\partial x}\left(\kappa(u) \frac{\partial u}{\partial x}\right)
$$

where $u(\mathrm{~kg} / \mathrm{kg})$ is the moisture content by mass, $t$ (s) the time of water absorption, and $x(\mathrm{~m})$ the distance from the water exposed surface of the sample.

The boundary and initial conditions were formulated as follows:

$$
\begin{aligned}
& u(0, t)=u_{1}, \\
& u(x, 0)=u_{2} .
\end{aligned}
$$

At the inverse analysis, Matano method was employed [8]. It is based on application of Boltzmann transformation, which is possible to be used in time intervals, when the real boundary condition on the dry end of the specimen is not yet effective and the problem can be considered as semi-infinite from the mathematical point of view. The advantage of the Boltzmann transformation

$$
u(x, t)=\omega(\eta),
$$




$$
\eta=\frac{x}{2 \sqrt{t}},
$$

consists of converting the partial differential Eq. (8) into the ordinary differential equation in new parameter $\eta$,

$$
\frac{d}{d \eta}\left(\kappa(\omega) \frac{d \omega}{d \eta}\right)+2 \eta \frac{d \omega}{d \eta}=0
$$

with the boundary conditions

$$
\omega(0)=u_{1}, \omega(\infty)=u_{2} .
$$

Eq. (9) cannot be solved analytically for arbitrary $\kappa(u)$ function, but a solution of ordinary differential equation is in any case much simpler than a solution of partial differential equation. If the moisture distribution $u(x)$ in time $t=t_{0}$ is known from the experiment, the relation for moisture dependent moisture diffusivity can be formulated as [9]

$$
\kappa\left(u_{x}\right)=\frac{1}{2 t_{0}\left(\frac{d u}{d x}\right) x_{x_{0}}} \int_{x_{0}}^{\infty} x \frac{d u}{d x} d x
$$

where $u_{x}=u\left(x_{0}\right)$.

For the calculation of moisture dependent moisture diffusivity, new software tool called K-Spline presented in [10] was used. This software tool enables to process laboratory determined data by spline curve. Spline curve can be understood as piecewise polynomial curve between defined control points. In this way, the experimental data are smoothed and Boltzmann- Matano method is applied. The smoothing process brings higher accuracy to the inverse method.

There were two basic sources of errors in the determination of moisture diffusivity. The first was the uncertainty of moisture measurement, the second was error of the calculation method. Naturally, the error due to the material inhomogeneity had to be added to the above two. The error in measuring moisture content was significantly reduced because of the application of the gravimetric method which belongs to the direct methods.

As the uncertainty of moisture measurements could be estimated as only $5 \%$, the main uncertainty was due to the calculation method and due to the material inhomogeneity that was, in the case of mineral wool, very high. Taking into account the detailed error analysis of the Matano method which was done in [11], and the dispersion of data observed for the mineral wool in this paper, the total uncertainty in moisture diffusivity determination could be characterized as $15 \%$.

\subsection{FTIR and chromatographic analyses}

The Fourier Transform Infrared (FTIR) Spectroscopy analysis of HMW leached at water was performed in order to verify the assumed leachability of the hydrophilic additive. The measurement was done using Spectrometer Nicolet 6700 (Thermo Fischer Scientific, Italy). Its spectral range varies between 7800 
and $3501 / \mathrm{cm}$ with spectral resolution $0.41 / \mathrm{cm}$. This equipment contains pyroelectric detector HP DLaTGS, KBr beamsplitter. The mirrors are golden diamond wrought and the light source is high-intensity source EverGloTM.

The Fourier Transform Infrared Spectroscopy (FTIR) means that data are collected and converted from an interference pattern to a spectrum using Fourier transformation. FTIR is the most powerful tool for identifying types of chemical bonds (functional groups). The wavelength of light absorbed is characteristic of the chemical bond as can be seen in this annotated spectrum. For the measurement, the ATR diamond cell was used with 64 scans per minute. The ATR technique (Attenuated Total Reflectance), also called as FMIR technique (Frustrated Multiple Internal Reflectance), is based on principle of multiple total reflexion of radiance on phase interface between analysed sample and measured high refractive index crystal. This crystal has planar shape of trapezoidal prism. Analysed sample is in thorough contact with ATR crystal, it absorbs radiation of specific frequency, and hence this frequency is totally attenuated in reflexed radiance. The penetration depth is several micrometers in dependence of crystal type, it comes to this, that only very thin surface layer is analysed.

Also the ion chromatographic analysis of the leach was done. It allows analysis of aqueous samples in parts-per-million (ppm) quantities of common anions, such as fluoride, chloride, nitrite, nitrate, and sulphate, and common cations like lithium, sodium, ammonium, and potassium, using conductivity detectors. The ion chromatography greatest utility is for analysis of anions for which there are no other rapid analytical methods, for example sulphates. It is also commonly used for cations and biochemical species such as amino acids and proteins. It is the most precisely analytical methods for very low ions concentrations determination. Liquid-solid adsorption chromatography is one of the forms of liquid chromatography in which the stationary phase is a solid adsorbent. In our case glass column was filled with hydroxyethylmethacrylate sorbent which is stable for $\mathrm{pH} 2-12$. For anion concentration measurement with suppression as a mobile phase $1 \mathrm{mM} \mathrm{Na} \mathrm{CO}_{3}$ and $8 \mathrm{nMNaHCO} \mathrm{M}_{3}$ were used. Tested solution was filtered into the syringe in order remove solid particles. The filtered solution was diluted and with Hamilton syringe injected into Rheodyne Injection Kit. Here, vacuum pump Chrom sds 150 was applied. For the conductivity measurement, device Shodex CD-5 was used with the data transducer COLIBRICK. As the solution conductivity is highly affected by its temperature, temperature around the detector cell was kept at a constant level by the temperature control system using a heater.

\section{Results and discussion}

The results of the basic physical properties of tested HMW materials are given in Table 1.

The obtained high porosity is the reason for the low thermal conductivity of the HMW, but also enables high water vapour transport, what is necessary for application of the tested materials in desalination of salt laden masonry. The matrix density data corresponds with the values typical for basalt. 
Table 1: Basic physical properties of HMW materials.

\begin{tabular}{|c|c|c|c|}
\hline Material & $\begin{array}{c}\text { Bulk density } \\
\left(\mathrm{kg} / \mathrm{m}^{3}\right)\end{array}$ & $\begin{array}{c}\text { Porosity } \\
(\%)\end{array}$ & $\begin{array}{c}\text { Matrix density } \\
\left(\mathrm{kg} / \mathrm{m}^{3}\right)\end{array}$ \\
\hline Commercial HMW (as sold) & 95.0 & - & - \\
\hline Soft part of commercial HMW & 79.5 & 96.9 & 2557 \\
\hline Hard part of commercial HMW & 172.4 & 93.4 & 2602 \\
\hline
\end{tabular}

In Fig. 1, the drying positions at room temperature for reusing the samples for liquid uptake experiment are described. The sample dried over a surface is taken from the equipment for sorption experiment and placed over the surface in the same position, whereas the sample dried in the vertical position is placed the bottom part turn up. The same positions where investigated while drying at $60^{\circ} \mathrm{C}$ in an oven.

The moisture transport measured within the sorption experiment is shown in Fig. 2 for the case of 3 samples (AV1, AV2, AV3) dried at room temperature in the vertical position. Here, indication 1,2, and 3 means number of repetitions

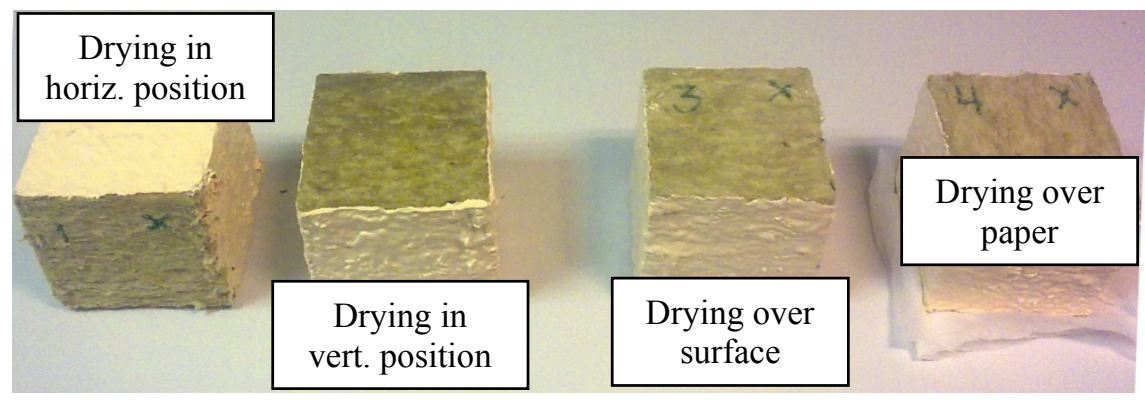

Figure 1: Drying positions.

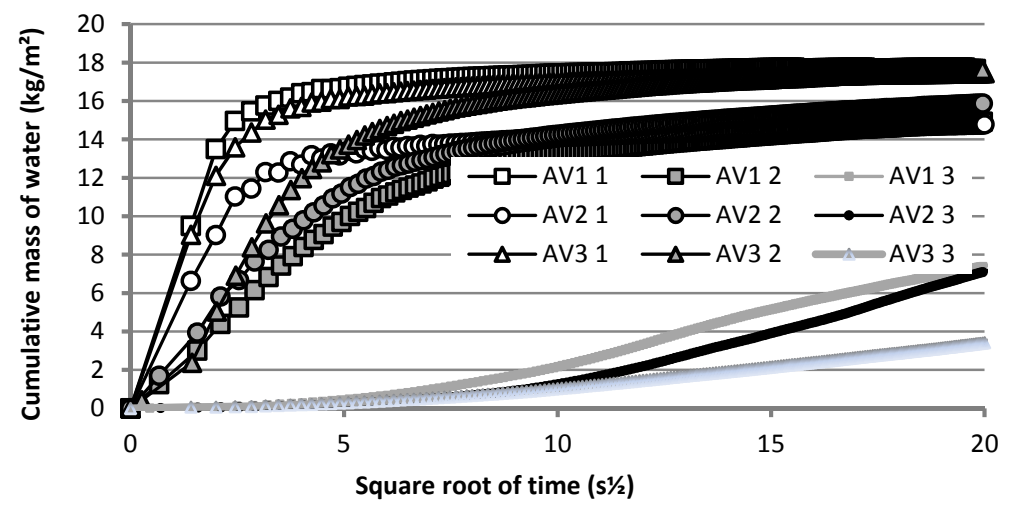

Figure 2: The course of sorptivity experiment for samples dried at room temperature in the vertical position. 
of sorption experiments for particular researched samples. From this data, the values of water absorption coefficient were calculated. Similar curves were obtained for different drying positions, drying at $60^{\circ} \mathrm{C}$, and suction of $1 \mathrm{M} \mathrm{NaCl}$ solution.

The results of the liquid moisture transport parameters are summarized in Table 2. Here, the transport of water or salt solution was realized perpendicularly to the orientation of fibre layers. The wetting cycles are numbered starting from 1 (new sample) up to 5, which corresponds to reusing the sample 4 times.

Table 2: Water and $1 \mathrm{M} \mathrm{NaCl}$ water solution transport parameters, A $\left(\mathrm{kg} / \mathrm{m}^{2} \mathrm{~s}^{1 / 2}\right), \kappa_{\text {app }}\left(\mathrm{m}^{2} / \mathrm{s}\right)$.

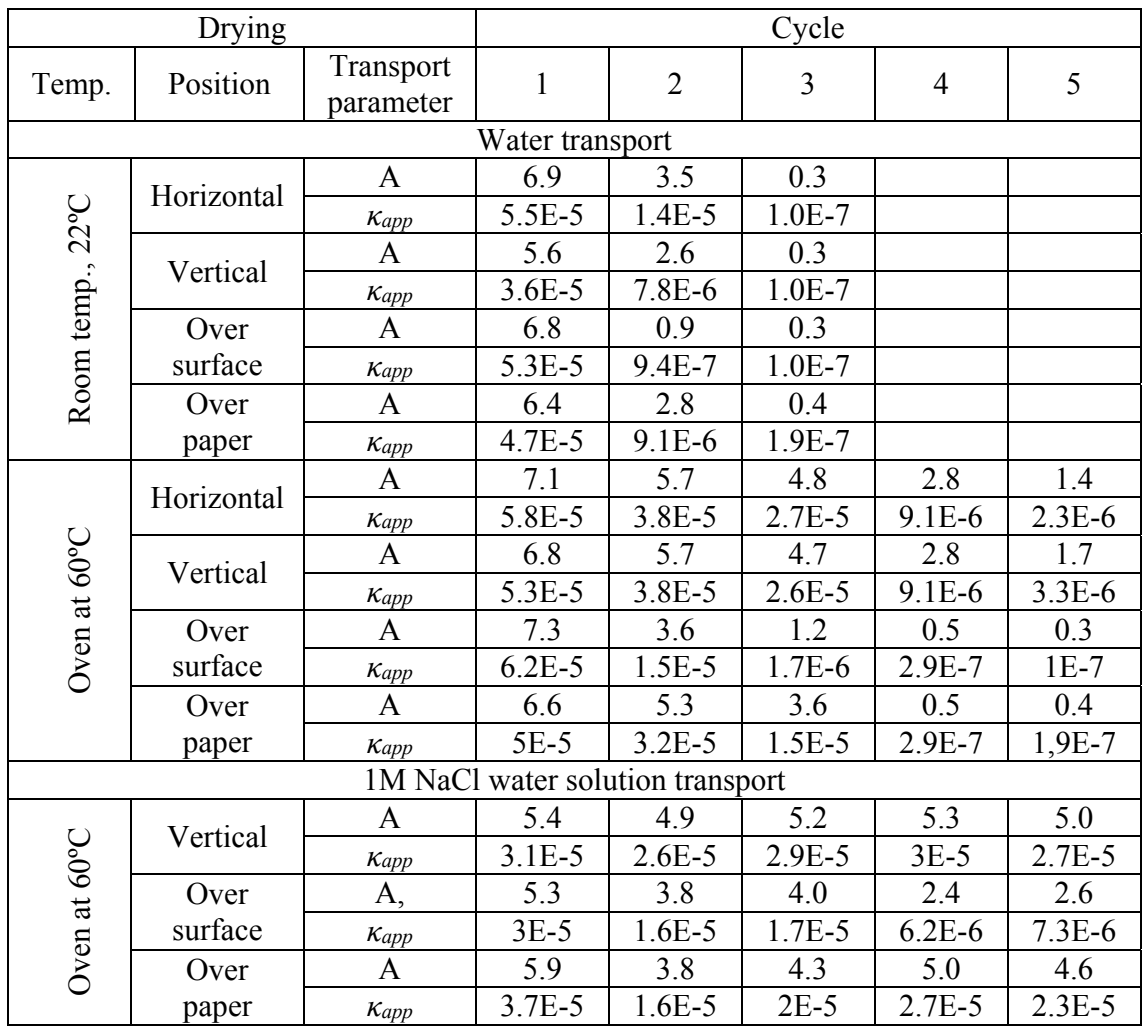

Water absorption coefficients accessed for the water uptake fell in every of the drying conditions as the sample is reused more and more times. What's more, each of the values is an average of 3 measurements, and all the samples behaved in the same way. This fall is more pronounced for samples dried at room temperature and for those dried over a surface as they are taken from the weighing scale. Those are the samples that drying takes longer or they are wet longer: around one day for all the samples dried into the oven, except the ones dried over a surface which are dry after two days and a half, around one week for 
samples dried at room temperature, except the ones dried over a surface which are dry after several weeks. This can be affecting the hydrophilic additive.

In the case of $1 \mathrm{M} \mathrm{NaCl}$ water solution transport, the moisture transport for new samples was slightly slower compared to the transport of pure water. The higher viscosity and density of salt solution than of water can be the reason for this, although the transport of the solution is still very high.

After wetting-drying cycles the solution absorption coefficients also fell, but this fall is only noticeable for the samples dried over a surface as they are taken from the weighing scale as with pure water. The remaining salt inside the used sample dried into the oven may be absorbing water and increasing the solution absorption coefficient.

As for pure water, the solution absorption coefficient of those samples that drying takes longer (or they are wet for longer times) fell really rapidly. The drying of samples dried over a surface as they are taken from the weighing scale takes two days and a half, and less than one day for the rest of the drying positions.

Moisture diffusivity as a function of moisture content for samples of new and reused HMW is shown in Fig. 3.

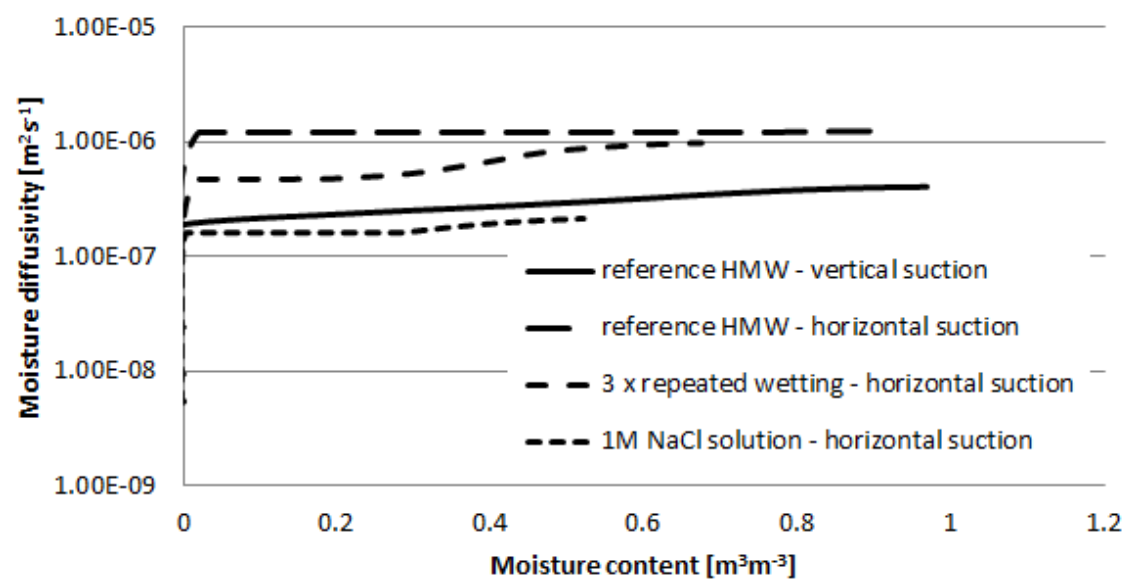

Figure 3: Moisture diffusivity in dependence on moisture content.

Also in this case, the accessed moisture diffusivity fell after repeated wetting compared the results obtained for reference sample without water exposure. Looking at this data one can observe high difference in moisture diffusivity measured in vertical and horizontal arrangement of suction experiment. Here, the gravity significantly reduces the rate of moisture transport and this effect must be considered in practical application of tested HMW. The moisture diffusivity function calculated for suction of $1 \mathrm{M} \mathrm{NaCl}$ solution was again lower than moisture diffusivity function obtained for pure water. This is in agreement with above given values of water absorption coefficient and apparent moisture diffusivity. 
Since the presence of organic hydrophilic substances was assumed in the analysed material, FTIR analysis was performed. Nevertheless, the presence of organic compounds was not clearly identified by FTIR measurements. Therefore, additional chromatographic analysis of HMW leach in water was done. The measured retention times corresponding to the presence of searched anions are given in Table 3. See Fig. 4 for calibration column performance.

Table 3: $\quad$ Measured retention times.

\begin{tabular}{|c|c|c|c|}
\hline Anion type & chlorides & fluorides & sulphates \\
\hline Retention time (min.) & 3.790 & 2.840 & 13.490 \\
\hline
\end{tabular}

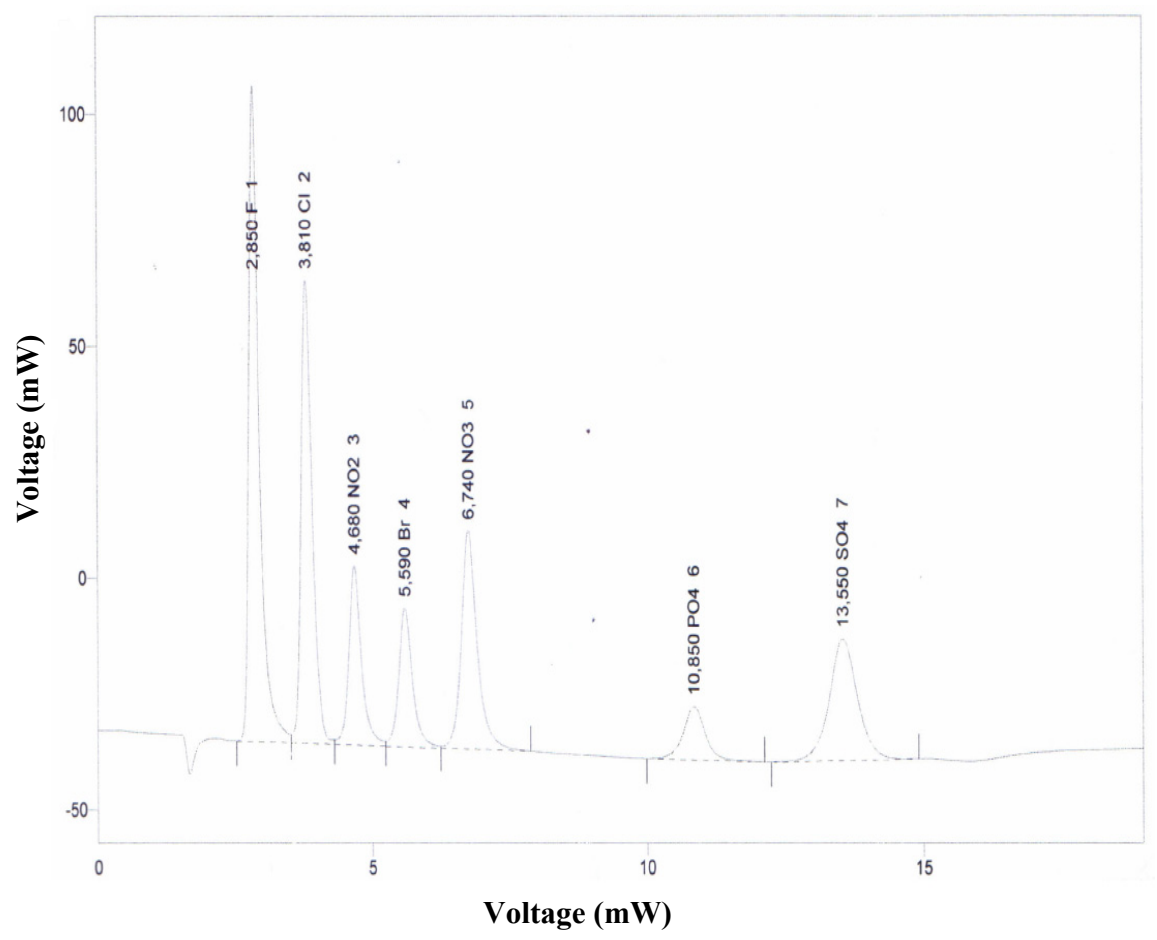

Figure 4: Calibration column performance.

The obtained results gave the evidence of the presence of sulphates, fluorides, and chlorides in the HMW leach. This proved the partial leaching of the hydrophilic substance from HMW that led to the deceleration of water and salt solution transport in researched material. In patent of Rockwool CZ [12], there is stated that preferred hydrophilic substances for HMW are anionic sulphate surfactants and anionic sulphonate surfactants, anionic carboxylate surfactants and anionic soap surfactants, what is in agreement with the data of ion chromatography analysis. 


\section{Conclusions}

The behaviour of the hydrophilic additive of HMW in the relation to the wetting-drying cycles was experimentally studied. The water and chloride absorption coefficients, as well as the corresponding moisture diffusivities were found very high for new samples without water exposure, which was beneficial for the application of HMW as a poultice material for desalination. However, after the exposure to repeated wetting-drying cycles in water, the observed water absorption coefficients dropped. The longer the reused sample was wet, the more rapidly water transport parameters fell. This finding documented that the hydrophilic additive of those samples whose drying took longer was affected by the presence of water more significantly.

The performed ion chromatography analysis proved the partial leaching of the hydrophilic substance from the HMW which essentially reduced a repeating application of HMW in desalination of building structures and historical monuments. It should be noted that the salts remaining inside the used HMW after its drying may be absorbing water and increasing the salt solution absorption coefficient but in principal, HMW may be useless for desalination when it is full of salts; it may not be taking the salts out from the masonry.

In future experiments, the presumed good properties of HMW for desalination of salt-laden masonry are supposed to be demonstrated on practical example of building structure suffering from salt presence and action.

\section{Acknowledgement}

This research was supported by the European social fund within the framework of realizing the project "Support of inter-sectorial mobility and quality enhancement of research teams at Czech Technical University in Prague", project No. CZ.1.07/2.3.00/30.0034.

\section{References}

[1] Antepara, I., Pavlík, Z., Žumár, J., Pavlíková, M., Černý, R. Properties of hydrophilic mineral wool for desalination of historical masonry, Materials science (Medžiagotyra), in press.

[2] Jim, C.Y., Tsang, S.W. Modeling the heat diffusion process in the abiotic layers of green roofs, Energy and Buildings, 43(6), pp. 1341-1350, 2011.

[3] Maděra, J., Černý, R. Computational Simulation of a Non-Traditional Method for Drying-Out of Building Envelopes Affected by Flood, Roczniki Inzynierii Budowlanej, Vol. 6, pp. 71-74, 2006.

[4] Mertz, J.D., Loutrel, P., Le dessalement des tuffeaux du chateau des duc de bretagne a nantes par a méthode de nettoyage Tollis. Pierre Actual, 779(7), pp. 68-75, 2001.

[5] Hall, C., Water sorptivity of mortars and concretes: a review, Magazine of Concrete Research, 41, pp. 51-61, 1989. 
[6] Roels, S., Carmeliet, J., Hens, H., Adan, O., Brocken, H., Černý, R., Pavlík, Z., Hall, C., Kumaran, K., Pel, L., \& Plagge R., Interlaboratory comparison of hygric properties of porous building materials, Journal of Thermal Envelope and Building Science, 27, pp. 307-325, 2004.

[7] Kumaran, M.K., Moisture diffusivity of building materials from water absorption measurements, Journal of Thermal Envelope and Building Science, 22, pp. 349-355, 1999.

[8] Matano, C., On the Relation between Diffusion Coefficients and Concentrations of Solid Metals, Japanese Journal of Physics, 8(3), pp.109-113, 1933.

[9] Pavlík, Z., Fiala, L., Maděra, J., Pavlíková, M., Černý, R., Computational modelling of coupled water and salt transport in porous materials using diffusion-advection model, Journal of the Franklin Institute, 348(7), pp. 1547-1587, 2011.

[10] Kočí, J., Pavlík, Z., Černý, R., Comparison of Two Different Modes of Inverse Analysis Used For Determination of Moisture Diffusivity of Building Materials, Advanced Materials Research, 982, pp. 49-53, 2014.

[11] Pavlík, Z., Černý, R., Determination of Moisture Diffusivity as a Function of Both Moisture and Temperature, International Journal of Thermophysics, 33(8), pp. 1704-1714, 2012.

[12] Cuypers, J. M. W., de Kubber, D. L., Mineral wool growth substrate and its use, Rockwool International A/S. EP1961291 A1., 2008. 